\title{
Research on Financial Efficiency of Yunnan Baiyao Based on Big Data
}

\author{
Xuefeng $\mathrm{Li}^{1, \mathrm{a}}$ \\ ${ }^{1}$ Department of Economics and Management, Longdong college, Gansu Qingyang, China
}

\begin{abstract}
The analysis of corporate financial efficiency can meet the different decision needs of users of accounting information. Big data transforms accounting information from real-time data to real-time cloud computing platforms, providing a rich information foundation for financial efficiency analysis of enterprises. This article uses the financial data of Yunnan Baiyao in the past six years, and analyzes the problems and countermeasures of its financial management by analyzing the company's operating capacity, profitability, solvency and development ability, in order to provide useful reference for enterprise management.
\end{abstract}

\section{Introduction}

The rapid development of information technology has promoted the widespread application of big data in corporate financial management. Its advantages are not only the ability to quickly provide accurate and diverse data, but also to connect it by analyzing the inherent correlation of data in different fields, which is a financial Management activities provide strong information and technical support[1].The widespread application of big data in financial analysis is not only an inevitable product of intelligent information processing, but also an effective way to improve the financial management level of enterprises. Financial efficiency analysis is an important part of corporate financial management. By analyzing the profit, operation, debt repayment and development ability of accounting entities, the decisionmaking needs of different users of accounting information are met. Yunnan Baiyao Group Co., Ltd. (hereinafter referred to as Yunnan Baiyao) is a largescale modern pharmaceutical group with a number of national first-class Chinese medicine protection varieties and technology patents. Diversified marketing strategies have made the company's performance among the peers. However, due to the increasing downward pressure on the macro economy, the company's operating costs have increased in recent years, the scale of receivables has increased, the efficiency of capital operations has decreased, and corporate financial management is facing severe tests.

Foreign research on the application of big data technology in financial analysis began in 2003. The results mainly focus on the functions and innovations of financial intelligence in computer science, engineering, management science and other fields. The application of big data technology in financial management Insufficient research [2]. This research in China started in 2015. There are 193 journal papers on the topic of "big data" and "financial analysis" in China HowNet. There are only 12 core journal papers. The research direction is mainly qualitative issues such as the construction of big data financial sharing platforms, the change of financial management concepts, and the adjustment of financial analysis perspectives. There are few research results on the micro level of financial analysis of big data, and it is rare to see the application of big data in the financial analysis of specific enterprises the study. While big data technology brings a lot of business data to financial analysis, the virtualized data environment also makes the financial analysis environment more complicated. How to effectively use big data technology to strengthen financial efficiency analysis and prevent and resolve financial risks is not only conducive to improving corporate management and economic benefits, but also conducive to ensuring the safe operation of China's macro economy under the new normal economy, and has important practical significance and academic value.

\section{Financial Efficiency Analysis of Yunnan Baiyao}

The users of corporate financial reports in our country mainly make corporate managers, investors, creditors, government departments and stakeholders. Different financial information users have different financial analysis purposes and different emphasis. Financial analysis includes two aspects: financial statement analysis and financial efficiency analysis. Among them, financial efficiency analysis mainly uses ratio analysis and factor analysis to comprehensively analyze the business management and development capabilities of enterprises. Satisfy the analysis and decision-making needs of different analysis entities on various aspects

alixf730615@163.com 
such as corporate profitability, operating efficiency, debt repayment, and development potential. Using financial and non-financial data, structured and unstructured data, macro and micro data provided by big data technology, a comprehensive financial efficiency analysis of Yunnan Baiyao Group can be performed.

\subsection{Profitability Analysis}

Profitability is a measure of the company's operating results and reflects shareholder value. It is the focus of financial analysis for corporate managers, investors and creditors. Using the relevant income and profit data from 2013 to 2018, the profitability analysis table for Yunnan Baiyao compiled is shown in Table 1.

TABle 1 YunNan BaiYaO's ProfitabiLity ANALysis Form 2014-2018

\begin{tabular}{c|c|c|c|c|c}
\hline Indicator name & $\mathbf{2 0 1 8}$ & $\mathbf{2 0 1 7}$ & $\mathbf{2 0 1 6}$ & $\mathbf{2 0 1 5}$ & $\mathbf{2 0 1 4}$ \\
\hline Roe (\%) & 17.28 & 17.44 & 18.57 & 20.63 & 22.41 \\
\hline Sales margin (\%) & 12.32 & 12.88 & 13.08 & 13.29 & 13.27 \\
\hline Roa (\%) & 13.18 & 14.05 & 14.61 & 17.37 & 18.33 \\
\hline $\begin{array}{c}\text { Operating income margin } \\
(\%)\end{array}$ & 14.35 & 14.89 & 14.81 & 15.28 & 15.04 \\
\hline Operating cost margin (\%) & 16.48 & 17.21 & 17.62 & 18.14 & 17.93 \\
\hline Surplus cash ratio (\%) & 79.94 & 36.89 & 101.84 & 79.09 & 63.54 \\
\hline
\end{tabular}

a. The data in this article are from Yunnan Baiyao Group Co., Ltd. 2013-2018 financial report without special instructions.

Analyzing the data in Table 1, it can be seen that although Yunnan Baiyao's operating income and operating costs increased significantly from 2014 to 2018. However, the year-on-year growth rate varies greatly from year to year, and the growth affecting operating profit and net profit also fluctuates. In sharp contrast to the output indicators, the company's net assets have grown steadily in the past five years. In 2018, it increased by 8.86236 million yuan compared to 2014 , with an average annual growth rate of $15.24 \%$. The core evaluation index, which affects the return on net assets, has decreased year by year, and the company's capital operating profitability has decreased significantly.

The profitability of assets of an enterprise is measured by the total return on assets indicator. As the company's net sales margin and total asset turnover rate have decreased year by year, the return on total assets has fallen by as much as $5.15 \%$ in the past five years. In recent years, due to the increase in labor and material costs, the profit margin of operating costs has always been higher than the profit margin of operating income, and the company's profitability of commodity operations has also decreased year by year. Earnings cash ratio can be used to evaluate the profitable cash recovery level. Except that the company's earnings cash ratio in 2017 was lower than the average level of its peers, the cash repayment levels in other years were relatively high and relatively stable, indicating that the company has good earnings quality and relatively abundant cash flow.

\subsection{Operational capacity analysis}

The ability to evaluate the company's asset operation efficiency is the focus of attention of investors, internal managers and creditors, as well as the attention of other users of financial information. Operating capacity depends on the speed of asset turnover, measured by the level of asset turnover. Table 2 shows the analysis indicators of Yunnan Baiyao's operating capacity from 2014 to 2018 based on big data.
TABLE 2 YUNNAN BAIYAO'S OPERATING CAPACITY ANALYSIS FORM FROM 2014 TO 2018

\begin{tabular}{l|l|l|l|l|l}
\hline $\begin{array}{l}\text { Indicator } \\
\text { name }\end{array}$ & $\mathbf{2 0 1 8}$ & $\mathbf{2 0 1 7}$ & $\mathbf{2 0 1 6}$ & $\mathbf{2 0 1 5}$ & $\mathbf{2 0 1 4}$ \\
\hline $\begin{array}{l}\text { Total asset } \\
\text { turnover }\end{array}$ & 0.92 & 0.93 & 1.02 & 1.06 & 1.29 \\
\hline $\begin{array}{l}\text { Turnover rate } \\
\text { of current } \\
\text { assets }\end{array}$ & 1.02 & 1.03 & 1.15 & 1.34 & 1.51 \\
\hline $\begin{array}{l}\text { inventory } \\
\text { turnover }\end{array}$ & 1.99 & 2.15 & 2.51 & 2.72 & 2.70 \\
\hline $\begin{array}{c}\text { Accounts } \\
\text { receivable } \\
\text { turnover }\end{array}$ & 17.30 & 21.65 & 21.66 & 25.72 & 34.48 \\
\hline $\begin{array}{l}\text { Turnover rate } \\
\text { of fixed assets }\end{array}$ & 15.20 & 13.35 & 12.72 & 12.19 & 12.39 \\
\hline
\end{tabular}

It can be seen from Table 2 that although the decrease in the turnover rate of Yunnan Baiyao's total assets has declined in recent years, the downward trend was obvious, indicating that the operating capacity of total assets has decreased. Although the company's current assets ratio has not changed much in recent years, the current asset turnover rate has dropped significantly, which has become the main reason for the slowdown in the turnover rate of total assets. The company's fixed asset management has achieved remarkable results. In recent years, it has basically shown a trend of accelerated turnover. In 2018, due to the company's consolidation of fixed assets, its turnover rate increased by $13.86 \%$ yearon-year.

The turnover rate of the company's inventory and accounts receivable has shown a significant decline in recent years. especially in 2018 , due to the increase in the accounts receivable and inventory scale by $50.22 \%$ and $15.37 \%$,its turnover and operating costs have only increased by $9.84 \%$ and $10.86 \%$, respectively, as a result, their turnover ratios were reduced by $4.35 \%$ and $0.16 \%$, the highest declines in recent years, which affected the turnover rate of current assets. Due to the slowdown in the turnover of current assets, in 2018, the company's 
operating income be relatively reduced by 23585.63 ten thousand yuan, the occupation of current assets increased by 25372.80 ten thousand yuan. In addition, Yunnan Baiyao's accounts receivable turnover rate was significantly faster than the accounts payable turnover rate in recent years. Savings in monetary funds will accelerate the turnover of current assets, which helped to improve the company's total asset operating capacity [3].

\subsection{Solvency analysis}

Debt funds are one of the main sources of corporate funds. Solvency is not only related to the survival and development of the enterprise, but also to the asset security of creditors. According to the debt maturity, the solvency analysis includes both long-term and short-term aspects. Table 3 shows the calculation results of Yunnan Baiyao's solvency analysis indicators from 2014 to 2018.

TABle 3 Yunnan Baiyao 2014-2018 DebT Solvency AnAlysis Form

\begin{tabular}{l|l|l|l|l|l}
\hline Indicator name & $\mathbf{2 0 1 8}$ & $\mathbf{2 0 1 7}$ & $\mathbf{2 0 1 6}$ & $\mathbf{2 0 1 5}$ & $\mathbf{2 0 1 4}$ \\
\hline Current ratio & 2.68 & 3.34 & 3.28 & 3.61 & 3.57 \\
\hline Quick ratio & 1.70 & 2.18 & 2.25 & 2.41 & 2.30 \\
\hline Cash ratio (\%) & 29.62 & 35.44 & 48.89 & 56.67 & 51.36 \\
\hline Assets and liabilities(\%) & 34.42 & 34.51 & 35.56 & 29.87 & 30.88 \\
\hline Interest coverage ratio & 24.43 & 50.93 & 38.88 & 246.22 & 192.7 \\
\hline
\end{tabular}

Short-term solvency is the decisive factor for corporate financial risk, and current ratio is the core indicator of short-term solvency. Yunnan Baiyao's current ratios were greater than 2 in the past five years, indicating that the company's short-term debt repayment ability was higher than the accepted standard; quick ratios were greater than 1, indicating that the company had sufficient realizable assets to pay off liabilities; cash ratios were greater than 0.2 , indicating that the cash flow which was used to settle debts was relatively abundant. As the idle cash assets will increase operating costs, the size of the company's cash assets should not be too large. Therefore, although the company's cash ratio in 2018 has decreased significantly, the degree of utilization of cash assets has increased.

The asset-liability ratio is a core evaluation indicator of a company's long-term debt service ability. It is often used to measure the degree of debt protection of all assets. In recent years, Yunnan Baiyao's asset-liability ratio has been below $50 \%$, which was at a medium level in the same industry, indicating that it has a long-term debt repayment ability and a sound business strategy. The company's share of short-term debt in 2018 increased to $97.43 \%$. Not only the debt maturity was short, but also the scale of interest-bearing debt was large. The debt repayment risk still exists. The degree of debt interest protection is usually measured by the interest protection multiples. In recent years, the indicator has fluctuated and fluctuated, especially in the past three years, the increase in interest expenses has caused the indicator to drop significantly, and the degree of interest protection was not as good as before.

\subsection{Development Capability Analysis}

The development ability is used to evaluate the future development potential and development trend of the company, and it is particularly concerned by enterprise managers, investors and government departments. Using the information provided by the financial big data, and adopting the calculation method of the period-by-period growth rate, the calculated analysis indicators of Yunnan
Baiyao's development capability from 2014 to 2018 are shown in Figure 1.

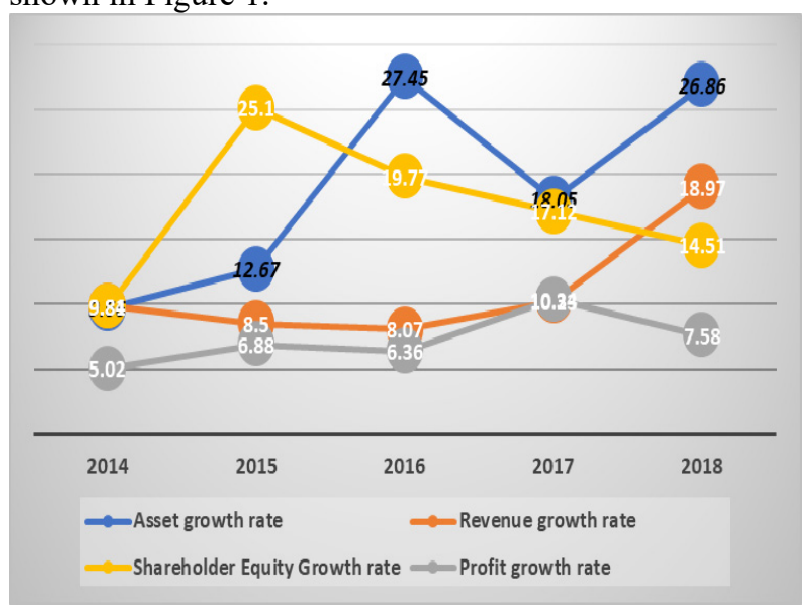

Figure 1. Analysis of Yunnan Baiyao's development capacity from 2014 to 2018 (Unit:\%)

Judging from a single development capability, in recent years, Yunnan Baiyao has been at the middleupper level of its peers. Among them, the development capabilities of assets, profits and shareholders' equity were showing a downward trend. In 2018, the company's shareholders' equity declined sharply, with a growth rate of only $9.81 \%$ and a decrease of $60.92 \%$; the profit growth rate has generally declined in fluctuations; although revenue growth has declined, after two consecutive years of slower growth, the revenue growth rate in 2018 increased by $1.34 \%$ compared to 2017 , and the development trend is more optimistic.

From the perspective of overall development capabilities, first, the company's revenue growth rate from 2014 to 2017 was less than the asset growth rate. It showed that the growth of income mainly depends on the investment of assets. This development did not have good benefits. Only the growth rate of income in 2018 was greater than the growth rate of assets. It should be maintained to strive for less input and more output. Secondly, the company's shareholder equity growth rate in the past five years was greater than the profit growth 
rate, indicating that the growth of net assets was not mainly derived from profit, and the company's development had not been well coordinated. Finally, the company's individual growth rates of assets, income, profits and shareholders' equity in recent years has maintained synchronous growth, and all were higher than the industry average. It can be considered that the company's overall development capacity was good and had the potential for sustainable growth[4].

\section{Problems and Countermeasures of Financial Management of Yunnan Baiyao Group}

\subsection{Problem}

1) The management concept is relatively traditional. Yunnan Baiyao has expanded its asset scale in recent years, but it has not brought about a simultaneous increase in revenue. The growth rate of profit and shareholder equity has shown a downward trend year-onyear. The increase in investment has not won the company a competitive advantage. The company's production technology transformation and upgrading are slow, and its core competitiveness is insufficient. Compared with the traditional business model, it lags significantly behind the rapidly changing market demand. The concept of financial management lags behind, and resources cannot be fully integrated by means of absorption and merger. Due to the slow implementation of the equity incentive mechanism, the enthusiasm of senior executives has not been fully mobilized.

2) Operating costs continue to increase. First, affected by factors such as the macroeconomic environment and market fluctuations, employees' expectations for wages have increased, and the company's labor costs have increased significantly. Secondly, in order to meet market demand, the company has increased research and development of new products and introduced machinery and equipment. These non-current asset investments require a large number of funding sources. The company's funding costs and expenses will inevitably rise, and financial costs will continue to increase. Finally, the increase in product transportation costs and increased publicity expenses to increase market share have increased the company's sales expenses.

3) Asset utilization is low. Enterprises can accelerate the turnover of total assets by increasing the proportion of current assets. Yunnan Baiyao's current assets accounted for about $90 \%$ in recent years, which is at the forefront of its peers. However, due to poor utilization of current assets, it has affected the turnover of total assets. The intensified competition makes the company's account receivables continuously expand, the account recovery costs continue to increase, and the risk of bad debts and operating pressures increase.

4) Increased potential operating risks. Corporate financial management emphasizes diversified operations, but Yunnan Baiyao focuses its business on pharmaceutical products, and its relatively single business model is not conducive to avoiding business risks. Cash assets generated in the course of operation are an important source of funds for corporate investment. Yunnan Baiyao implements a stable business strategy, and its business methods are relatively traditional. Cooperating with other enterprises is relatively small, and the scale of external investment is limited, so the abundant cash flow does not bring corresponding investment income, but instead leads to the company's unreasonable asset structure.

\section{2 solutions}

1) Innovative corporate management concepts. First of all, we should seize the good opportunities of traditional Chinese medicine products with less side effects on the epidemic, learn from the successful experience of large domestic and foreign pharmaceutical companies, timely adjust business models based on their own characteristics, cultivate new products, expand marketing channels, stimulate endogenous motivation, and find new growth point. Secondly, we should integrate high-quality tea, health care and other industrial chain assets, give play to industry synergies, build the core competitiveness of the pharmaceutical and health industry, and deepen the reform of mixed ownership to integrate resources to enhance the right to speak in industrial M \& A. Finally, we should optimize the organizational structure, clarify the functions of the department, continue to implement the employee stock ownership plan, bind the long-term interests of the company and the core team, and improve management efficiency.

2) Reduce operating costs. In the control of production costs, the amount of inventory should be determined scientifically, raw material inventory should be reduced without affecting production, and inventory of finished products should be reduced through market research and optimization of product structure, as well as inventory purchase and inventory costs; should strengthen the skills training of front-line employees, improve labor productivity and reduce labor costs; machinery and equipment should be regularly overhauled and improved to improve the utilization rate of fixed assets. In the period cost control, the examination and approval system for management expenses should be strictly implemented; optimize financing methods, make full use of short-term debt to save financial costs; accelerate the integration of marketing resources, expand marketing channels to reduce sales expenses.

3) Optimize current asset management. In inventory management, we should rely on the supply chain system of ERP software to accurately grasp the inventory outbound and inbound inventory, ensure production and sales supply, and avoid overstocking and impairment of inventory; the inventory management system should be implemented to strengthen the key management of 
important inventory to ensure physical security. In the management of receivables, the credit sales line should be determined in strict accordance with the customer's credit rating, and the internal control system of accounts receivable should be improved and implemented to the sales and financial management departments; the collection of accounts receivable should be strengthened and timely and fully accrued Provision for bad debts. In the management of monetary funds, on the premise of ensuring expenditures, investment in key projects should be used to promote the company's technological transformation and upgrading, and avoid idle funds.

4) Prevent corporate business risks. First of all, we should conduct objective analysis of company external factors such as industry market demand and cost changes, and increase investment in research and development of medical device products and four seasons health products, establish key breed groups, improve product technical content, diversification of the company through external investment. Secondly, we should improve the financial system and internal control system, strengthen financial supervision and internal audit of the company, and effectively prevent and control business risks through comprehensive risk management.

\section{Conclusion}

Yunnan Baiyao's recent years of revenue and profit realization were based on high investment, lack of efficiency and coordinated growth. The company's operating capacity and profitability were not optimistic.
It is necessary to change the operating philosophy, establish a sense of risk, and effectively improve the company Sustainable development capabilities. Big data technology enables financial information not only covers industry and product market data, but also extends from financial statement data to a diverse and related data collection. Financial management should be based on the actual needs, after the data is filtered and then stored centrally. Financial analysis should ensure data security technically and conceptually, and prevent corporate financial data and business data from being leaked or tampered with. This is also an important issue for enterprise management in the era of big data.

\section{References}

1. Zhang Hongying, Wang Cuisen. Opportunities and Challenges in the Field of Financial Analysis in the Era of Big Data[J]. Finance and Accounting Newsletter, 2016 (05): 84-85.

2. Zhang Chao, Xiao Cong. Visual Analysis and Literature Review of Financial Intelligence[J]. Finance and Accounting Monthly, 2019 (03): 24-32.

3. Luo Xiaona, Li Anlan, etc. Methods to Reduce the Bias and Decision Misunderstanding of Financial Index Analysis[J]. Finance and Accounting Newsletter, 2019 (11): 94-97.

4. Zhang Xianzhi, Chen Youbang. Financial Analysis (8th Edition) [M]. Dongbei University of Finance and Economics Press, 2017: 251-252. 